\title{
Dependence of Detonation Velocity of Explosives on Effective Atomic Number and Effective Electron Density of the Explosives
}

\author{
Tohe Tessema Teklemariam, Vijay Kumar Mittal* \\ Department of Physics, Jimma University, Jimma, Ethiopia \\ Email address: \\ teklema@yahoo.ca (T. T. Teklemariam), teklemariam.tessema@aau.edu.et (T. T. Teklemariam), Vijay_52_Mittal@yahoo.com (V. K. Mittal) \\ ${ }^{*}$ Corresponding author
}

\section{To cite this article:}

Tohe Tessema Teklemariam, Vijay Kumar Mittal. Dependence of Detonation Velocity of Explosives on Effective Atomic Number and Effective Electron Density of the Explosives. American Journal of Physics and Applications. Vol. 8, No. 5, 2020, pp. $73-77$. doi: 10.11648/j.ajpa.20200805.12

Received: September 21, 2020; Accepted: November 6, 2020; Published: November 19, 2020

\begin{abstract}
Detonation velocity is one of the most important characteristics of explosives. For solid hydro carbon-based explosives it is generally greater than $4000 \mathrm{~m} / \mathrm{s}$. Detonation velocity depends to some extent upon the particle size of the explosives, increased charge diameter and increased confinement of the explosive. There is no report indicating the dependence of detonation velocity on the effective atomic number and effective electron density of the explosive. In the present work, we have arbitrarily chosen eight explosives. Four of these have detonation velocity between 9400 and $10100 \mathrm{~m} / \mathrm{s}$, and the other four has detonation velocity between 4500 and $5300 \mathrm{~m} / \mathrm{s}$. Direct method was used to calculate effective atomic number and effective electron densities various explosives. On calculating effective atomic number and effective electron density, it was found that detonation velocity of explosives does depend upon these two parameters. For explosives with high detonation velocity, effective atomic number is high and effective electron density is low while for low detonation velocity explosives it is reverse. It was also found that the variation of effective atomic number and effective electron density as a function of gamma ray energy can be explained on the basis of three different gamma ray inter action mechanism of gamma rays with matter.
\end{abstract}

Keywords: Explosives, Detonation Velocity, Effective Atomic Number, Effective Electron Density

\section{Introduction}

An explosive is defined as a chemical compound which, when subjected to heat, impact, etc. undergoes very rapid, self-propagating, heat- producing decomposition. This decomposition produces gases that exert tremendous pressures as they expand at the high temperature of the reaction creating a fast moving wave front. Detonation Velocity (DV) or explosive velocity, also known velocity of detonation, is the velocity at which this shock wave front travels through the detonated explosive.

Solid explosives often have detonation velocities ranging between $4000 \mathrm{~m} / \mathrm{s}$ to $10100 \mathrm{~m} / \mathrm{s}$ [1].

Low explosives are compounds where the rate of decomposition proceeds through the material at less than the speed of sound i. e. shock wave front passes through the material at sub sonic speed [1].

High explosives (HE) are explosive materials that detonate, meaning that the explosive shock front passes through the material at a supersonic speed [1].

Explosive velocity increases with smaller particle size of the explosive, increased charge diameter, and increased confinement (i.e. higher pressure).

In literature there is no report indicating that detonation velocity depends upon the effective $Z\left(Z_{\text {eff }}\right)$ or effective electron density $\left(\mathrm{N}_{\text {eff }}\right)$ of the explosive. However, in literature there is one report where the effective $Z$ and effective electron density of some commonly used explosives has been reported [2].

Therefore, in the present work we have decided to study the effect of effective atomic number $Z_{\text {eff }}$ and effective electron density $\mathrm{N}_{\text {eff }}$ of the explosive on the DV. For this we 
have chosen two types of explosives. The first category consists of explosives with high DV $(>9400 \mathrm{~m} / \mathrm{s})$ and the second is with relatively small DV $(\sim 4500$ to $5300 \mathrm{~m} / \mathrm{s})$. For these two categories of explosives, we calculated the effective atomic number and effective electron densities.

Many researchers have made extensive effective atomic number and effective electron density studies on a variety of materials. For example, effective atomic number and effective electron densities were evaluated in composite materials like dosimetric materials [3, 4], alloys [5, 6], semiconductors [7, 8], glasses [9], biological samples [10], gamma ray detectors [11], liquid crystals [12], narcotic drugs
$[13,14]$ etc.

\section{Methodology}

The first category includes explosives where the DV is > $9400 \mathrm{~m} / \mathrm{s}$. These are ONC, DDF, HHTDD and HMX. In the second category are the explosives with common name as TAPP, MEKP, UN and HMTD with DV between $4500 \mathrm{~m} / \mathrm{s}$ to $5300 \mathrm{~m} / \mathrm{s}$. These are shown in Table 1 and are taken from Wikipedia [15]. This table also shows the common name, chemical formula, density and detonation velocity of the chosen explosives.

Table 1. Common name, chemical formula of explosives chosen in the present work. Densities and detonation velocities are also displayed in the table.

\begin{tabular}{|c|c|c|c|c|}
\hline Explosive & $\begin{array}{l}\text { Chemical } \\
\text { formula }\end{array}$ & Common name IUPAC name & $\begin{array}{l}\text { Density } \\
\left(\mathrm{g} / \mathrm{cm}^{3}\right)\end{array}$ & $\begin{array}{l}\text { Detonation } \\
\text { velocity }(\mathrm{cm} / \mathrm{s})\end{array}$ \\
\hline \multicolumn{5}{|c|}{ High detonation velocity } \\
\hline $\mathrm{ONC}$ & $\mathrm{C}_{8} \mathrm{~N}_{8} \mathrm{O}_{16}$ & Octanitrocubane & 1.979 & 10,100 \\
\hline DDF & $\mathrm{C}_{4} \mathrm{~N}_{8} \mathrm{O}_{8}$ & $\begin{array}{l}\text { 4,4'-Dinitro-3,3'-diazenofuroxan (E)-4-nitro-N-[(E)-(4-nitro-2-oxo-1,2,5-oxadiazol- } \\
\text { 2-ium-3-ylidene)amino]-2-oxido-1,2,5-oxadiazol-3-imine }\end{array}$ & 2.02 & 10,000 \\
\hline HHTDD & $\mathrm{C}_{6} \mathrm{H}_{4} \mathrm{~N}_{12} \mathrm{O}_{14}$ & $\begin{array}{l}\text { Hexanitrohexaazatricyclododecanedione 2,6-Dioxo-1,3,4,5,7,8-hexanitrodecahydro- } \\
1 \mathrm{H}, 5 \mathrm{H} \text {-diimidazo[4,5-b:4',5'-e]pyrazine }\end{array}$ & 2.16 & 9700 \\
\hline HMX & $\mathrm{C}_{4} \mathrm{H}_{8} \mathrm{O}_{8} \mathrm{~N}_{8}$ & Her Majesty's Explosive 1,3,5,7-Tetranitro-1,3,5,7-tetrazoctane & 1.91 & 9400 \\
\hline \multicolumn{5}{|c|}{ Low detonation velocity } \\
\hline TAPP & $\mathrm{C}_{9} \mathrm{H}_{18} \mathrm{O}_{6}$ & triacetone triperoxide 3,3,6,6,9,9-Hexamethyl-1,2,4,5,7,8-hexaoxacyclononane & 1.18 & 5300 \\
\hline MEKP & $\mathrm{C}_{8} \mathrm{H}_{18} \mathrm{O}_{6}$ & Methyl ethyl ketone peroxide 2,2'-Peroxydi(butane-2-peroxol) & 1.17 & 5200 \\
\hline UN & $\mathrm{CH}_{5} \mathrm{~N}_{3} \mathrm{O}_{4}$ & Urea nitrate & 1.69 & 4700 \\
\hline HMTD & $\mathrm{C}_{6} \mathrm{H}_{12} \mathrm{O}_{6} \mathrm{~N}_{2}$ & $\begin{array}{l}\text { Hexamethylene triperoxide diamine 3,4,8,9,12,13-Hexaoxa-1,6- } \\
\text { diazabicyclo[4.4.4]tetradecane }\end{array}$ & 1.57 & 4500 \\
\hline
\end{tabular}

Calculation for effective atomic numbers and effective electron densities were done by direct method as discussed in detail in our earlier publications $[11,12]$. Mass attenuation coefficients needed for these calculations were evaluated by WinXCom software [16].

Below, a brief discussion of the method used for evaluating effective $\mathrm{Z}$ and effective electron density is presented.

This method uses the concept of gamma attenuation when it passes through a material media [17]. Intensity (I) of the attenuated beam is related to its unattenuated beam intensity $\left(\mathrm{I}_{0}\right)$ by the Lambert-Beers law given in (1).

$$
I=I_{0} e^{-\mu x}
$$

Where $\mathrm{x}$ is the thickness of the material in ' $\mathrm{cm}$ ' and $\mu$ is its linear attenuation coefficient in $\mathrm{cm}^{-1}$. The mass attenuation coefficient of the material $\left(\mu_{\mathrm{m}}\right)$ was obtained from the value of its linear attenuation coefficient $\mu$ and density $(\rho)$ of the material as given in (2) [17].

$$
\mu_{m}=\frac{\mu}{\rho}
$$

Since the materials under study (explosives) are composite materials, total $\mu_{\mathrm{m}}$ of the explosive is given by the relation (3) [17]. Where $\mathrm{w}_{\mathrm{i}}$ is the weight fraction of the $\mathrm{i}^{\text {th }}$ element.

$$
\mu_{m}=\sum_{i} w_{i} \frac{\mu_{i}}{\rho_{i}}
$$

To find the total weight fraction of each of the element in the explosives under study, an equation of weight fraction for composite materials, (4) was used.

$$
w_{i}=\frac{n_{i} A_{i}}{\sum_{i} n_{i} A_{i}}
$$

Satisfying $\sum_{i} w_{i}=1$

Where $A_{i}$ and $n_{i}$ are the atomic weight and the number formula units of the $i^{\text {th }}$ element in the explosives, respectively.

The WinXCom software was used to obtain mass attenuation coefficient of the explosives understudy [16].

The results obtained from calculations of mass attenuation coefficients were used to find for the total atomic crosssection $\sigma_{\mathrm{t}}$ using (5) [18].

$$
\sigma_{t}=\frac{\mu_{m} M}{N_{A}}
$$

Where $M$ is the atomic mass of the material and $N_{A}$ is Avogadro's number. For each of the explosive total electronic cross sections which depend on the total mass attenuation coefficient were obtained using (6). Total electronic crosssection $\sigma_{\mathrm{e}}$ for a particular explosive and its total atomic cross sections are related as shown in (6) [19].

$$
\sigma_{e}=\frac{1}{N_{A}} \sum_{i} \frac{f_{i} A_{i}}{Z_{i}} \mu_{m}=\frac{\sigma_{t}}{Z_{\text {eff }}}
$$

Where $f_{i}$ is the fractional abundance of the element $\mathrm{i}$ with respect to the number of atoms such that $\sum_{i} f_{i}=1$.

Finally, the ratio of total atomic cross-section $\sigma_{\mathrm{t}}$ and total electronic cross-section $\sigma_{\mathrm{e}}$, as in (7), was used to find the effective atomic number of the crystals. 


$$
Z_{\text {eff }}=\frac{\sigma_{t}}{\sigma_{e}}
$$

Number of electrons per unit mass (effective electron density) was determined using the relation given in $(8)[19,20]$.

$$
N_{e f f}=\frac{\mu_{m}}{\sigma_{e}}
$$

In brief our calculations of the effective atomic number and effective electron densities are bases on the following formulas presented in (7) and (8).

\section{Results}

Plot of mass attenuation coefficients for all the explosives as a function of energy are shown in Figure 1. All these curves are almost overlapping. So, it is not possible to draw any conclusion from these curves.

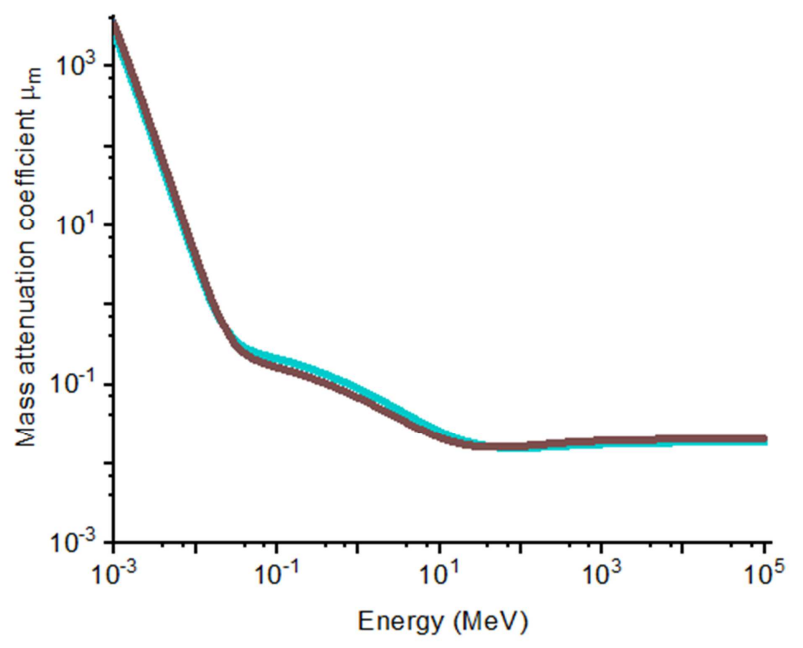

Figure 1. Mass attenuation coefficients for all the 8 explosives.

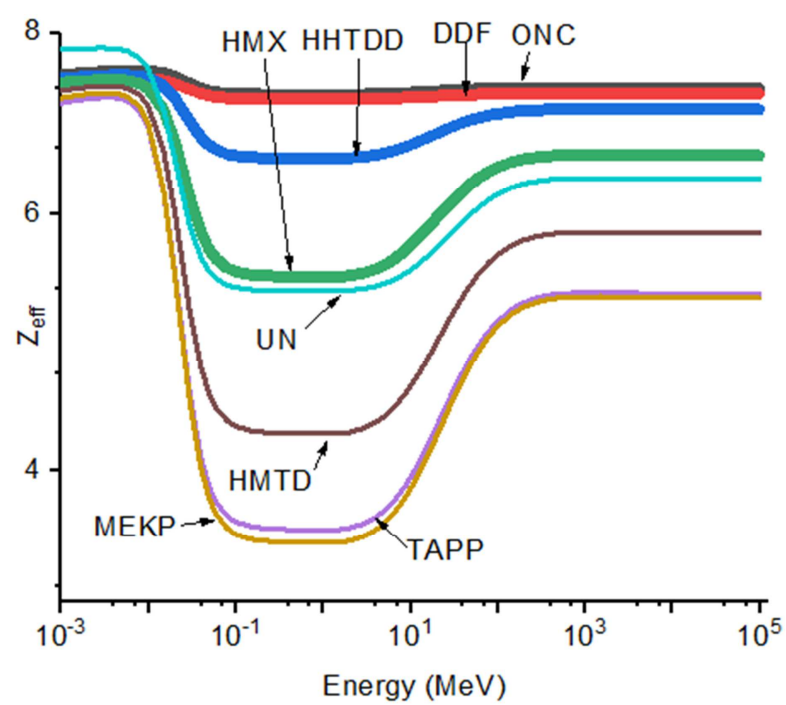

Figure 2. $Z_{\text {eff }}$ vs. Energy of gamma rays. Thick curves are for high detonation velocity explosives, whereas thin curves are for low detonation velocity explosives.

In Figure 2, plot of $\mathrm{Z}_{\mathrm{eff}}$ versus energy $(\mathrm{MeV})$ for different explosives are shown. Thicker lines correspond to the four explosives namely ONC, DDF, HHTDD and HMX. These are the explosives with DV> $9400 \mathrm{~m} / \mathrm{s}$. The other four thinner curves are for explosives UN, HMTD, TAPP and MEKP. For these explosives the DV is between 4500 to 5300 $\mathrm{m} / \mathrm{s}$. From the figure one can conclude that effective atomic nu mver of high detonation velocity explosives is higher than those with low detonation velocity.

From Figure 2, it is evident that at low energy $(<0.01$ $\mathrm{MeV}), Z_{\text {eff }}$ for all the explosives has a high value. In the energy range between 0.01 to $0.1 \mathrm{MeV}, Z_{\text {eff }}$ decreases fast. Further in the energy range between 0.1 to about $10 \mathrm{MeV}, \mathrm{Z}_{\text {eff }}$ remains almost constant. Beyond this energy, it increases relatively slowly to attain a constant value.

In Figure 3 effective electron density as a function of gamma ray energy is shown for eight different explosives. As in Figure 2, thicker lines correspond to the four explosives namely ONC, DDF, HHTDD and HMX having high DV. The thinner curves are for explosives UN, HMTD, TAPP and MEKP having low DV. From the figure it is quite clear that for explosives with high DV, effective electron density is lower than those with low DV.

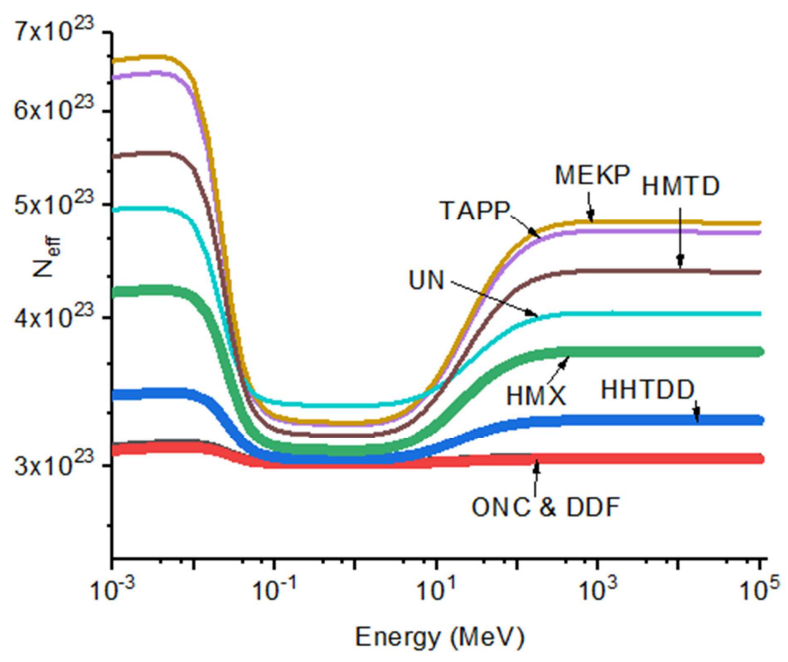

Figure 3. $N_{\text {eff }}$ vs. Energy of gamma rays. Thick curves are for high detonation velocity explosives, whereas thin curves are for low detonation velocity explosive.

The behavior of $Z_{\text {eff }}$ and $\mathrm{N}_{\text {eff }}$ as a function of $\gamma$-ray energy can be explained on the basis of partial importance of $\gamma$-ray interaction processes with matter. Gamma ray mainly interacts with matter is via three different processes i. e. photo electric effect, Compton scattering and pair production

In low energy region, photo electric effect dominates. In the intermediate region Compton scattering dominates and in the high energy region pair production is the main $\gamma$-ray interaction process.

In low energy region $0.01<\mathrm{E}<0.5 \mathrm{MeV}$, cross section for photo electric effect behaves as

$E^{-3.5}$. The values of $Z_{\text {eff }}$ and $N_{\text {eff }}$ also decreases almost in the same manner as photo electric cross section. Compton effect is negligibly small and probability of pair production is zero in this energy region. 
In the intermediate energy region $0.5<\mathrm{E}<5 \mathrm{MeV}$, cross section for Compton scattering increases as $\mathrm{E}$ and cross section for photo electric effect decreases as $\frac{1}{E}$. Cross section for pair production increases as $\log _{e}(E)$. The net result is that total photon interaction cross section almost remains constant in the region. Therefore, the values of $\mathrm{Z}_{\text {eff }}$ and $\mathrm{N}_{\text {eff }}$ practically remain constant in the region.

Finally, in the high energy range $\mathrm{E}>5 \mathrm{MeV}$ cross sections for photo electric effect and Compton scattering are negligibly small while pair production cross section increases as $\log _{e}(E)$. This increase is very slow and also it almost saturates for $\mathrm{E}>100 \mathrm{MeV}$. $\mathrm{Z}_{\text {eff }}$ and $\mathrm{N}_{\text {eff }}$ also show the similar behavior in this energy range.

\section{Conclusions}

In this experiment, we have arbitrarily chosen eight hydro carbon based organic explosives. Out of these, four have DV $>$ $9400 \mathrm{~m} / \mathrm{s}$ while the other four explosives have DV between 4500 and $5300 \mathrm{~m} / \mathrm{s}$. It has been found that for high DV explosives $Z_{\text {eff }}$ is higher than those with low DV. Effective electron density $\mathrm{N}_{\text {eff }}$, however is lower in high DV explosives compared to low DV explosives.

Therefore, looking at these eight explosives, we can conclude that DV of explosives depends upon the effective atomic number and effective electron density of the explosives.

\section{Acknowledgements}

The authors are thankful to the Department of Physics, College of Natural Sciences, Jimma University for providing necessary facilities and encouragement throughout the progress of this work.

\section{References}

[1] Peter Krehl, O. K. In 'History of Shock Waves, Explosions and Impact: A Chronological and Biographical Reference'. Springer Science \& Business Media. pp. 106. 2008.

[2] Shivraj Gounhalli, G. Anil Shantappa, and Hanagodimath, S. M. "Studies on effective atomic numbers and electron densities of some chemical explosives in the energy range $1 \mathrm{KeV}-100 \mathrm{GeV}$ ", Journal of Chemical and Pharmaceutical Research, 4, pp. 2545-2563, 2012.

[3] Vishwanath, P Singh and Badiger, N. M. (2016), Effective Atomic Number of Dosimetric Interest Organic Compounds, Indian J Pure and Applied Physics, 54, 333-338.

[4] Shivalinge, Gowda, Krishnaveni, S., Yashoda, T., Umesh, T. K. and Ramakrishna, Gowda (2004), Photon mass attenuation coefficients, effective atomic numbers and electron densities of some thermoluminescent dosimetric compounds. Pramana, $63,529-541$.

[5] Han, I., Aygun, M., Demir, L., and Sahin, Y. (2012), "Determination of effective atomic numbers for $3 \mathrm{~d}$ transition metal alloys with a new semi-empirical approach," Annals of Nuclear Energy, 39, 56-61.
[6] Kurudirek, M., Büyükyıldız, M., and Özdemir, Y. (2010), "Effective atomic number study of various alloys for total photon interaction in the energy region of $1 \mathrm{keV}-100 \mathrm{GeV}$," Nuclear Instruments and Methods in Physics Research A, 613, 251-256.

[7] Çelik, A., Çevik, U., Bacaksiz, E., and Çelik, N. (2008), "Effective atomic numbers and electron densities of $\mathrm{CuGaSe}_{2}$ semiconductor in the energy range 6-511 keV", X-Ray Spectrometry, 37, 490-494.

[8] Ïçelli, O. (2009), "Measurement of effective atomic numbers of holmium doped and undoped layered semiconductors via transmission method around the absorption edge", Nuclear Instruments and Methods in Physics Research A, 600, 635639.

[9] Kaewkhao, J. and Limsuwan, P. (2010), "Mass attenuation coefficients and effective atomic numbers in phosphate glass containing $\mathrm{Bi}_{2} \mathrm{O}_{3}, \mathrm{PbO}$ and $\mathrm{BaO}$ at $662 \mathrm{keV}$," Nuclear Instruments and Methods in Physics Research A: Accelerators, Spectrometers, Detectors and Associated Equipment, 619, 295-297.

[10] Manjunathaguru, V. and T. K. Umesh, T. K. (2006), "Effective atomic numbers and electron densities of some biologically important compounds containing $\mathrm{H}, \mathrm{C}, \mathrm{N}$ and $\mathrm{O}$ in the energy range 145-1330 keV," Journal of Physics B: Atomic, Molecular and Optical Physics, 39, 39693981 .

[11] Vegi, A. R. and Mittal, V. K. "Calculation of Atomic Parameters of Bismuth Germinate Detectors", J of Ultra Scientists of Physical Sciences B 30, pp. 81-87, 2018.

[12] Teklemariam, T. T., Mittal, V. K. and Chali Yedeta, 2019, "Atomic Parameters of Some Commonly Used Liquid Crystals", Ethiop J Educ and Science 14, 48-57, 2019.

[13] Kaçal, M. R., Akdemir, F., Araz, A., Mehmet Fatih Turhan and Ridvan Durak (2017), Calculation of Absorption Parameters for Selected Narcotic Drugs in the Energy Range from $1 \mathrm{keV}$ to $100 \mathrm{GeV}$ Ferdi Akman, AIP Conference Proceedings 1833, 020083.

[14] Gounhalli, S. G., Shantappa, A. and Hanagodimath, S. M. (2012), Studies on Mass Attenuation Coefficient, Effective Atomic Numbers and Electron Densities of Some Narcotic Drugs in the Energy Range $1 \mathrm{KeV}$ $100 \mathrm{GeV}$, Journal of Applied Physics (IOSR-JAP) 2 (2012), 40-48.

[15] https://en.wikipedia.org/wiki/Table_of_explosive_detonation velocity.

[16] Gerwards, L., Guilbert, N., Jensen, K. B. and Levring, H., 2004, "WinXCom - a program for calculating X-ray attenuation coefficients", Radiation Physics and Chemistry 71, 653-654, 2004.

[17] Madhusudhan Rao A. S., Narender K., Gopal Krishan Rao K., Gopi Krishna N., and Radha Krishna Murthy (2016). Mass attenuation coefficients, effective atomic and electron numbers of alkali halides for multi energetic photons. Research J Physical Sci, 1: 11-16.

[18] Singh K., and Gerward L., (2002). Summary of existing information of gamma ray and X-ray attenuation coefficients of solutions, Indian Journal of Pure and Applied Physics, 40 (9): 643-649. 
[19] Manohara S. R., Hanagodimath S., and Gerward L., (2008). Energy dependence of effective atomic number for photon energy absorption and photon interactions: study of some biological molecules in the energy range $1 \mathrm{keV}$ to $20 \mathrm{MeV}$, Medical Physics, 35 (1): 388-402.
[20] Gowda S., Krishnaveni S., and Gowda R. (2005). Studies on effective atomic numbers and electron densities in amino acids and sugars in the energy range $30-1333 \mathrm{keV}$, Nucl. Instrum. Methods B239: 361-369. 